\title{
Respiratory mechanics and morphometric changes during anesthesia with ketamine in normal rats
}

\author{
O. Alves-N eto ${ }^{1}$, \\ P. Tavares ${ }^{1}$ \\ P.R.M. Rocco ${ }^{2}$ \\ and W.A. Zin $^{2}$
}

\begin{abstract}
${ }^{1}$ Laboratório de Fisiologia Respiratória, Departamento de Clínica M édica, Faculdade de Ciências da Saúde, Universidade de Brasília, Brasília, DF, Brasil ${ }^{2}$ Laboratório de Fisiologia da Respiração, Instituto de Biofísica Carlos Chagas Filho, Universidade Federal do Rio de Janeiro, Rio de Janeiro, RJ, Brasil
\end{abstract}

\section{Correspondence \\ 0 . Alves-Neto \\ Rua T-61, 305, Apto. 301 \\ Setor Bueno \\ 74223-170 Goiânia, GO \\ Brasil \\ Fax: + 55-62-259-4996 \\ E-mail: onofre@ zaz.com.br}

Received January 2, 2001

Accepted July 2, 2001

\section{Abstract}

Ketamine is believed to reduce airway and pulmonary tissue resistance. The aim of the present study was to determine the effects of ketamine on the resistive, elastic and viscoelastic/inhomogeneous mechanical properties of the respiratory system, lungs and chest wall, and to relate the mechanical data to findings from histological lung analysis in normal animals. Fifteen adult male Wistar rats were assigned randomly to two groups: control $(\mathrm{N}=7)$ and ketamine $(\mathrm{N}=$ 8). All animals were sedated (diazepam, $5 \mathrm{mg}$, ip) and anesthetized with pentobarbital sodium $(20 \mathrm{mg} / \mathrm{kg}$, ip $)$ or ketamine $(30 \mathrm{mg} / \mathrm{kg}$, ip) The rats were paralyzed and ventilated mechanically. Ketamine increased lung viscoelastic/inhomogeneous pressure (26\%) compared to the control group. Dynamic and static elastances were similar in both groups, but the difference was greater in the ketamine than in the control group. Lung morphometry demonstrated dilation of alveolar ducts and increased areas of alveolar collapse in the ketamine group. In conclusion, ketamine did not act at the airway level but acted at the lung periphery increasing mechanical inhomogeneities possibly resulting from dilation of distal airways and alveolar collapse.
Key words

- Ketamine

- Elastance

- Lung tissue

- Resistive pressure

- Viscoelasticity

- Rat

\section{Introduction}

Ketamine is a general intravenous anesthetic that has been used since the sixties (1). It is a non-narcotic and non-barbiturate drug that induces sensorial dissociation in the patient. Especially due to its analgesic effects, ketamine is frequently used both in humans (2) and animals (3) either alone or in combination with other drugs.

The respiratory effects of ketamine (4) are noticeable, mainly involving bronchodilation (5), which was initially observed in asthmatic patients. Supposedly, ketamine relaxes the bronchiolar musculature and prevents the bronchoconstriction induced by histamine, which would be an obvious advantage for asthmatic patients. However, the effects of ketamine on the respiratory system in the absence of active smooth muscle tone need to be clarified.

In this context, in the present study, the mechanical properties of the respiratory system, lung, and chest wall were subdivided into their resistive, elastic, and viscoelastic components during ketamine anesthesia in 
normal rats in order to pinpoint the sites of action of this anesthetic agent. In addition, histopathological studies were performed to support the physiological findings. This multidisciplinary approach has not been used previously.

\section{Material and Methods}

Fifteen male adult Wistar rats were initially sedated with diazepam (5 mg, ip) and divided into two groups: control (CTRL, 280-300 g) - 7 rats anesthetized with pentobarbital sodium $(20 \mathrm{mg} / \mathrm{kg}$, ip) and study (KET, 270-310 g) - 8 rats anesthetized with ketamine $(30 \mathrm{mg} / \mathrm{kg}$, ip). In both groups the doses were enough to suppress the corneopalpebral reflex during the experiment, which lasted no longer than $40 \mathrm{~min}$.

After anesthesia, the animals were placed in the supine position on a surgical table. A snugly fitting cannula $1.5 \mathrm{~mm}$ in inner diameter and $6.8 \mathrm{~mm}$ in length was introduced into the trachea.

A pneumotachograph (6) (internal diameter $=1.5 \mathrm{~mm}$, length $=4.2 \mathrm{~cm}$, distance between side ports $=2.1 \mathrm{~cm}$ ) was connected to the tracheal cannula for airflow (V') measurements. The pressure gradient across the pneumotachograph was determined using a Validyne MP45-2 differential pressure transducer (Northridge, CA, USA). Volume (V) was obtained by integration of the flow signal. Equipment resistive pressure was subtracted from respiratory system and pulmonary resistive pressures so that the results reported reflect intrinsic mechanical properties. Because abrupt changes in diameter were not present in our circuit, errors of measurement of flow resistance were avoided. The equipment dead space was 0.4 ml.

Tracheal pressure (Ptr) was measured with a Hewlett-Packard 270 differential pressure transducer (Waltham, MA, USA). Changes in esophageal pressure (Pes), which reflects chest wall pressure $(\mathrm{Pw})$, were meas- ured with a $30-\mathrm{cm}$ long water-filled catheter (PE-240) with side holes at the tip connected to a PR23-2D-300 Statham differential pressure transducer (Hato Rey, Puerto Rico). The catheter was introduced into the stomach and then slowly returned into the esophagus and its proper positioning was assessed using the "occlusion test" (7). The frequency responses of the pressure measurement system (Ptr and Pes) were flat up to $20 \mathrm{~Hz}$, without an appreciable phase shift between signals. All signals were conditioned and amplified with a Beckman type R Dynograph (Schiller Park, IL, USA). Flow and pressure signals were also passed through 8-pole Bessel filters (902LPF, Frequency Devices, Haverhill, MA, USA) with the corner frequency set at $100 \mathrm{~Hz}$, sampled at $200 \mathrm{~Hz}$ with a 12-bit analogue-to-digital converter (DT2801A, Data Translation, Marlboro, MA, USA), and stored on a PC-compatible microcomputer. All data were collected using LABDAT software (RHT-InfoData).

Muscle relaxation was achieved with gallamine triethyliodide ( $2 \mathrm{mg} / \mathrm{kg}$, ip), and artificial ventilation was provided by a Salziner constant flow ventilator (Instituto do Coração, USP, São Paulo, SP, Brazil). During the test breaths, adjusting the ventilator settings generated a 5-s end-inspiratory pause, whereas during the baseline ventilation no pause was used. In order to avoid the effects of different flows and volumes (8) and inspiratory duration (9) on the variables measured, special care was taken to keep volume $(\mathrm{V}=2$ $\mathrm{ml})$ and flow $\left(\mathrm{V}^{\prime}=10 \mathrm{ml} / \mathrm{s}\right)$ constant in all animals. Breathing frequency remained constant and equal to 100 breaths/min during the experiment. The duration of inspiration $\left(\mathrm{T}_{\mathrm{I}}\right)$ was set at $0.2 \mathrm{~s}$ and the duty cycle $\left(\mathrm{T}_{\mathrm{I}} / \mathrm{T}_{\mathrm{T}}\right)$ lasted $0.33 \mathrm{~s}$.

Respiratory mechanics were measured by end-inspiratory occlusion after constant flow inflation (10). Briefly, after end-inspiratory occlusion, there is an initial fast drop in tracheal pressure $(\Delta \mathrm{P} 1, \mathrm{rs})$ from the pre-occlusion value down to an inflection 
point (Pi,rs), followed by a slow pressure decay $(\Delta \mathrm{P} 2, \mathrm{rs})$ until a plateau is reached. This plateau corresponds to the elastic recoil pressure of the respiratory system (Pel,rs). $\Delta \mathrm{P} 1$,rs selectively reflects the combination of airway, pulmonary and chest wall Newtonian resistances in normal animals (10-12) and in humans (13). $\Delta \mathrm{P} 2$,rs reflects stress relaxation, or viscoelastic properties of the lung and chest wall tissues, together with a small contribution of pendelluft in normal situations (10-13). The same applies to $\mathrm{Pw}$, yielding the values of $\Delta \mathrm{P} 1, \mathrm{w}, \mathrm{Pi}, \mathrm{w}$, $\Delta \mathrm{P} 2, \mathrm{w}$, and Pel,w, respectively. Transpulmonary pressures $(\Delta \mathrm{P} 1, \mathrm{~L}, \mathrm{Pi}, \mathrm{L}, \Delta \mathrm{P} 2, \mathrm{~L}$, and Pel,L) were calculated by subtracting the chest wall pressure from the corresponding values pertaining to the respiratory system. The total pressure drop ( $\Delta \mathrm{Ptot})$ is equal to the sum of $\Delta \mathrm{P} 1$ and $\Delta \mathrm{P} 2$, yielding the values of $\Delta$ Ptot,rs, $\Delta$ Ptot,L, and $\Delta$ Ptot,w. Respiratory system, lung, and chest wall static elastances (Est,rs, Est,L, and Est,w, respectively) were calculated by dividing Pel,rs, Pel,L, and Pel,w, by total volume (VT), respectively. Dynamic elastances of the respiratory system, lung and chest wall (Edyn,rs, Edyn,L, and Edyn,w, respectively) were obtained by dividing $\mathrm{Pi}, \mathrm{rs}, \mathrm{Pi}, \mathrm{L}$, and $\mathrm{Pi}, \mathrm{w}$, by $\mathrm{VT}$, respectively. $\Delta \mathrm{E}$ was calculated as the difference Edyn-Est, yielding the values of $\Delta \mathrm{E}, \mathrm{rs}, \Delta \mathrm{E}, \mathrm{L}$, and $\Delta \mathrm{E}, \mathrm{w}$. The data concerning respiratory system, lung, and chest wall elastances were presented in terms of static elastance and $\Delta \mathrm{E}$ instead of dynamic elastances, since they represent the elastic and viscoelastic properties of the respiratory system, respectively (9). Measurements of the respiratory mechanics were performed 8-10 times in each animal in all instances. Immediately before each data collection period, the airways were aspirated to remove possible collection of mucus, and the respiratory system was inflated three times to total lung capacity to maintain constant volume. The delay between the beginning and the end of valve closure $(10 \mathrm{~ms})$ was calcu- lated by back-extrapolation of the pressure records to the actual time of occlusion and the corrections in pressure, although very minute, were performed (8). All data were analyzed using the ANADAT data analysis software (RHT-InfoData).

Immediately after the determination of respiratory mechanics, with the animal still alive, the trachea was clamped at end-expiration, and the abdominal aorta and vena cava were sectioned, yielding a massive hemorrhage that quickly killed the animals. Functional residual capacity (FRC) was determined as follows: the lungs were rapidly surgically removed (on average, it took $90 \mathrm{~s}$ to remove them) and submerged into warm $\left(37^{\circ} \mathrm{C}\right) 0.9 \% \mathrm{NaCl}$ solution (saline), the volume displaced was recorded, and the lungs were weighed. FRC corresponds to the difference between the saline displaced (in $\mathrm{ml}$ ) and the lung weight (in g), assuming that the tissue and saline have identical densities, equal to $1.0 \mathrm{~g} / \mathrm{ml}$ (14).

After the measurements of FRC the lungs were quick-frozen by immersion in liquid nitrogen for morphometric study (15). Tissues were fixed in Carnoy's solution (ethanol:chloroform:acetic acid, 70:20:10, v/v) at $-70^{\circ} \mathrm{C}$ for $24 \mathrm{~h}$. Progressively increasing concentrations of ethanol at $-20^{\circ} \mathrm{C}$ were then substituted for Carnoy's solution until 100\% ethanol was reached. Tissues were maintained at $-20^{\circ} \mathrm{C}$ for $4 \mathrm{~h}$, warmed to $-4^{\circ} \mathrm{C}$ for $12 \mathrm{~h}$ and then allowed to reach and remain at room temperature for $2 \mathrm{~h}$. After fixation, tissue blocks obtained from midsagittal slices of the lungs at the level of the axial bronchus were embedded in paraffin and cut into 4$\mu \mathrm{m}$ thick sections with a microtome. Coded slices were stained with hematoxylin-eosin.

Microscopic examination was performed by two investigators who were unaware of the origin of the material during scoring. Morphometric analysis was performed with an integrating eyepiece with a coherent system made of a 100-point grid consisting of 50 lines of known length, coupled to a con- 
ventional light microscope. The volume fraction of collapsed and normal pulmonary areas, as well as the fraction of the lung occupied by large-volume gas-exchanging airspaces (hyperinflation - structures with a morphology distinct from that of alveoli and wider than $120 \mu \mathrm{m}$ ) were determined by the point-counting technique (15), carried out at 40X magnification across 10 random, noncoincident microscopic fields.

The internal diameter of the alveolar ducts was determined with the aid of a digital analysis system and specific software (Image-pro Plus 4.1, Media Cybernetics, Silver Spring, MD, USA) at 100X magnification.

Table 1. Respiratory data of rats anesthetized with pentobarbital sodium or ketamine.

\begin{tabular}{|c|c|c|}
\hline & CTRL & KET \\
\hline Flow (ml/s) & $10.16 \pm 0.40$ & $10.11 \pm 0.43$ \\
\hline Tidal volume (ml) & $2.04 \pm 0.05$ & $1.99 \pm 0.03$ \\
\hline $\mathrm{FRC}(\mathrm{ml})$ & $1.89 \pm 0.39$ & $2.14 \pm 0.65$ \\
\hline \multicolumn{3}{|l|}{ Respiratory system } \\
\hline$\Delta$ Ptot, rs $\left(\mathrm{cmH}_{2} \mathrm{O}\right)$ & $3.53 \pm 0.35$ & $4.28 \pm 0.62 *$ \\
\hline$\Delta \mathrm{P} 1, \mathrm{rs}\left(\mathrm{cmH}_{2} \mathrm{O}\right)$ & $1.91 \pm 0.19$ & $2.26 \pm 0.55$ \\
\hline$\Delta \mathrm{P} 2, \mathrm{rs}\left(\mathrm{cmH}_{2} \mathrm{O}\right)$ & $1.61 \pm 0.19$ & $2.01 \pm 0.32 *$ \\
\hline$\Delta \mathrm{E}, \mathrm{rs}\left(\mathrm{cmH}_{2} \mathrm{O} / \mathrm{ml}\right)$ & $0.78 \pm 0.10$ & $1.01 \pm 0.16^{*}$ \\
\hline Est,rs $\left(\mathrm{cmH}_{2} \mathrm{O} / \mathrm{ml}\right)$ & $3.15 \pm 0.26$ & $3.36 \pm 0.46$ \\
\hline \multicolumn{3}{|l|}{ Lung } \\
\hline$\Delta$ Ptot, $\mathrm{L}\left(\mathrm{cmH}_{2} \mathrm{O}\right)$ & $2.77 \pm 0.55$ & $3.56 \pm 0.72 *$ \\
\hline$\Delta \mathrm{P} 1, \mathrm{~L}\left(\mathrm{cmH}_{2} \mathrm{O}\right)$ & $1.47 \pm 0.31$ & $1.92 \pm 0.60$ \\
\hline$\Delta \mathrm{P} 2, \mathrm{~L}\left(\mathrm{cmH}_{2} \mathrm{O}\right)$ & $1.30 \pm 0.25$ & $1.64 \pm 0.29 *$ \\
\hline$\Delta \mathrm{E}, \mathrm{L}\left(\mathrm{cmH}_{2} \mathrm{O} / \mathrm{ml}\right)$ & $0.63 \pm 0.12$ & $0.82 \pm 0.15^{*}$ \\
\hline Est,L $\left(\mathrm{cmH}_{2} \mathrm{O} / \mathrm{ml}\right)$ & $2.33 \pm 0.36$ & $2.55 \pm 0.47$ \\
\hline \multicolumn{3}{|l|}{ Chest wall } \\
\hline$\Delta$ Ptot, w $\left(\mathrm{cmH}_{2} \mathrm{O}\right)$ & $0.75 \pm 0.24$ & $0.70 \pm 0.20$ \\
\hline$\Delta \mathrm{P} 1, \mathrm{w}\left(\mathrm{cmH}_{2} \mathrm{O}\right)$ & $0.44 \pm 0.15$ & $0.34 \pm 0.15$ \\
\hline$\Delta \mathrm{P} 2, \mathrm{w}\left(\mathrm{cmH}_{2} \mathrm{O}\right)$ & $0.30 \pm 0.11$ & $0.36 \pm 0.13$ \\
\hline$\Delta \mathrm{E}, \mathrm{w}\left(\mathrm{cmH}_{2} \mathrm{O} / \mathrm{ml}\right)$ & $0.14 \pm 0.05$ & $0.18 \pm 0.06$ \\
\hline Est, $\mathrm{w}\left(\mathrm{cmH}_{2} \mathrm{O} / \mathrm{ml}\right)$ & $0.80 \pm 0.19$ & $0.80 \pm 0.27$ \\
\hline
\end{tabular}

Values are reported as means \pm SD for 7 animals anesthetized with pentobarbital sodium (CTRL) and 8 rats anesthetized with ketamine (KET) (8-10 determinations/rat). $r \mathrm{~S}=$ respiratory system; $\mathrm{L}=$ lung; $\mathrm{w}=$ chest wall; $\Delta \mathrm{Ptot}, \Delta \mathrm{P} 1$ and $\Delta \mathrm{P} 2=$ total, resistive and viscoelastic/inhomogeneous pressures, respectively; Est $=$ static elastance; $\Delta \mathrm{E}=$ difference between dynamic and static elastances; FRC $=$ functional residual capacity. $* \mathrm{P}<0.05$ compared to the CTRL group (Student ttest).
The images were generated by a microscope (Axioplan, Zeiss, Oberkochen, Germany) connected to a camera (Trinitron CCD, Sony, Tokyo, Japan), fed into a computer through a frame grabber (Oculus TCX, Coreco Inc., St. Laurent, PQ, Canada) for off-line processing.

The luminal area of the central airways was computed by counting the points falling on the airway lumen and the points falling on airway smooth muscle and on the epithelium. The perimeters of the airways were estimated by counting the intercepts of the lines of the integrating eyepiece with epithelial basement membrane. This procedure was repeated four times for each airway. The areas of smooth muscle and airway epithelium were corrected in terms of airway perimeter by dividing their values by the number of intercepts of the line system with the epithelial basement membrane of the corresponding airway. Because the number of intercepts (NI) of the lines with epithelial basement membrane is proportional to the airway perimeter and the number of points (NP) falling on the airway lumen is proportional to airway area, the magnitude of bronchoconstriction [contraction index (CI)] was computed by the equation: $\mathrm{CI}=\mathrm{NI} / \sqrt{\mathrm{N} P}$.

All animals received humane care in compliance with the "Principles of Laboratory Animal Care" formulated by the National Society for Medical Research and the "Guiding Principles in the Care and Use of Animals" approved by the Council of the American Physiological Society.

In order to compare the results obtained for the KET and CTRL groups the data were first tested for normality by the Kolmogorov-Smirnov test with Lilliefors' correction, and the homogeneity of variances was then tested by the Levene median test. If both conditions were satisfied, the Student $t$-test was used. Spearman correlation was used to correlate the functional parameters with the morphometric parameters. The significance level was always set at $5 \%$. 


\section{Results}

Flow and volume did not differ between the CTRL and KET groups (Table 1). Respiratory system and lung total pressure were increased in the KET group as a result of higher viscoelastic/inhomogeneous pulmonary pressure (Table 1). The dynamic and static elastances were similar in both groups. However, the difference between the dynamic and static elastances of the respiratory system and lungs were significantly higher in the KET than in the CTRL group.

The mean $( \pm$ SEM $)$ percentages of normal, collapsed and hyperinflated areas, contraction index, and the internal diameter of the alveolar ducts in the CTRL and KET groups are shown in Table 2. It can be seen that ketamine anesthesia yielded a higher degree of alveolar collapse than those found in the CTRL group. In addition, the internal diameter of the alveolar ducts was higher in the KET than in the CTRL group. The internal diameter of the central airways was similar in both groups.

Considering the CTRL and KET groups together, viscoelastic/inhomogeneous pulmonary pressure was well correlated with the fraction of area of alveolar collapse $(\mathrm{P}=$ $0.04, r=0.6)$ and the internal diameter of alveolar ducts $(\mathrm{P}<0.0001, \mathrm{r}=0.85)$.

\section{Discussion}

The main finding of this study was that ketamine anesthesia increased pulmonary viscoelastic/inhomogeneous pressure in rats without pre-existing airway constriction. This result was supported by the histological demonstration of increased areas of alveolar collapse and dilation of alveolar ducts, which may yield a higher degree of inhomogeneities within the lung. In addition, ketamine anesthesia did not alter lung resistive pressure and there was no difference in the contraction index between CTRL and KET.

Ketamine is still considered the ideal anesthetic for asthmatic patients because it decreases the risk of bronchospasm during induction of anesthesia and preserves the pulmonary vasoconstriction reflex to hypoxia. Thus, it has been recently compared to the latest anesthetics, like propofol (3). Ketamine causes bronchodilation in both animals and humans, and exceptional results have been obtained in asthmatic patients (16).

Gallamine, an antagonist of muscarinic M2-type receptors, was used to produce neuromuscular block and many studies have shown that although the drug has anticholinergic properties, airway resistance is unchanged $(17,18)$. Recently, it has been demonstrated that gallamine and pentobarbital did not significantly alter lung morphometry in rats, with the mechanical properties probably being unchanged (19).

The great advantage of the end-inflation occlusion method is the possibility of partitioning the pressure used to insufflate the respiratory system and its pulmonary and chest wall components into their viscous or resistive $(\triangle \mathrm{P} 1)$, viscoelastic/inhomogeneous $(\Delta \mathrm{P} 2)$, and elastic (Pel) components. The influence of $\mathrm{V}$ ' and $\mathrm{V}$ on the mechanical parameters was demonstrated in several studies $(8,9)$. In the present experiments $V^{\prime}$ and $\mathrm{V}$ were similar in both groups, thus permitting a comparison of the results obtained for the CTRL and KET groups.

Table 2. Morphometric data of rats anesthetized with pentobarbital sodium or ketamine.

\begin{tabular}{lccccc}
\hline Group & Normal & $\begin{array}{c}\text { Alveolar } \\
\text { collapse }\end{array}$ & $\begin{array}{c}\text { Alveolar } \\
\text { hyperinflation }\end{array}$ & $\begin{array}{c}\text { Contraction } \\
\text { index }\end{array}$ & $\begin{array}{c}\text { Internal diameter } \\
\text { of alveolar } \\
\text { ducts }(\mu \mathrm{m})\end{array}$ \\
\hline CTRL & $90.5 \pm 0.9$ & $7.4 \pm 0.6$ & $2.2 \pm 0.4$ & $0.11 \pm 0.01$ & $99 \pm 4$ \\
KET & $84.2 \pm 1.2^{*}$ & $12.9 \pm 1.2^{*}$ & $2.9 \pm 0.5$ & $0.12 \pm 0.03$ & $151 \pm 10^{*}$ \\
\hline
\end{tabular}

Values are reported as means \pm SEM for 7 animals anesthetized with pentobarbital sodium (CTRL) and 8 rats anesthetized with ketamine (KET). All values are percentage of normal, collapsed and hyperinflated areas in 10 random, noncoincident fields per rat.

$* \mathrm{P}<0.05$ compared to the CTRL group (Student t-test). 
Since ketamine anesthesia did not alter pulmonary resistive pressure dissipation $(\Delta \mathrm{P} 1, \mathrm{~L})$ (Table 1$)$, we may conclude that airway resistance did not change (19). In addition, there was no difference in the internal diameters of central airways (contraction index) between the CTRL and KET groups, supporting the absence of changes in airway resistance.

Ketamine is traditionally considered to be a safe agent for asthmatic patients because it protects against bronchospastic attacks and resolves symptoms of acute asthma present at the time of induction (5). However, in the present study there was no functional or histological evidence of bronchodilation in normal rats anesthetized with ketamine. In this respect, Gateau et al. (20) reported that ketamine did not influence the basal tone of human bronchial preparations but antagonized bronchial contraction produced by histamine and acetylcholine. The diversity of methods used to determine lung resistance, the variability in lung volume and respiratory frequency, the differences in lung preparations (in vivo versus in vitro), and the smooth muscle tone of the airways may lead to discrepant results.

As shown in Table 1, ketamine anesthesia significantly increased pulmonary viscoelastic/inhomogeneous pressure. Lung histology showed enlarged alveolar ducts, together with alveolar collapse (Table 2). The precise effect of ketamine on lung periphery is not known. Ketamine may dilate alveolar ducts, thus changing the geometry of the alveoli and yielding atelectasis. This hypothesis is supported by the correlation between $\triangle \mathrm{P} 2, \mathrm{~L}$ and the internal diameter of alveolar ducts and the fraction of alveolar collapse. On the other hand, alveolar collapse may pull open alveolar ducts. Under these conditions the distribution of ventilation could be altered, increasing mechanical inhomogeneities.

Ketamine did not alter Est,L (Table 1), thus indicating that the pulmonary elastic component of the respiratory impedance did not change under the present experimental conditions. Functional residual capacity remained unchanged in our study (CTRL: 1.89 $\pm 0.39 \mathrm{ml} v \mathrm{~s}$ KET: $2.14 \pm 0.65 \mathrm{ml}$ ), in agreement with some reports indicating that ketamine is unique in its ability to maintain FRC upon the induction of anesthesia $(21,22)$.

$\Delta \mathrm{E}, \mathrm{rs}$ and $\Delta \mathrm{E}, \mathrm{L}$ increased significantly during ketamine anesthesia (Table 1), suggesting that lung (and thus respiratory system) viscoelasticity/inhomogeneity became more prominent under the action of this anesthetic agent. This finding was confirmed by the increase in $\Delta \mathrm{P} 2, \mathrm{~L}$ (Table 1), as discussed above.

In summary, we confirmed that ketamine does not act at the airway level but at the lung periphery. Ketamine anesthesia in rats without pre-existing airway constriction increased the viscoelastic/inhomogeneous pressures applied to the lung. This finding was supported by the histological demonstration of increased areas of alveolar collapse and dilation of alveolar ducts.

\section{References}

1. McCarthy DA, Cheng G, Kaump DH \& Ensor C (1965). General anesthetic and other pharmacological properties of 2-(Ochlorophenyl)2-methylamino-cyclohexanone $\mathrm{HCl}(\mathrm{Cl}-581)$. J ournal of New Drugs, 5: 21-33.

2. Schmid RL, Sandler NA \& Katz J (1999). Use and efficacy of low-dose ketamine in the management of acute postoperative pain: a review of current techniques and outcomes. Pain, 82: 111-125.

3. Brown RH \& Wagner EM (1999). Mechanisms of bronchoprotection by anesthetic induction agents: propofol versus ketamine. Anesthesiology, 90: 822-828.

4. Zsigmond EK, Matsuki A \& Kotharey SP (1976). Arterial hypoxemia caused by intravenous ketamine. Anesthesia and An- algesia, 55: 311-314.

5. Corssen G, Gutierrez JJ, Reves J G \& Huber J r FC (1972). Ketamine in the anesthetic management of asthmatic patients. Anesthesia and Analgesia, 51: 588-596.

6. Mortola J P \& Noworaj A (1983). Two-sidearm tracheal cannula for respiratory airflow measurements in small animals. J oumal of Applied Physiology, 55: 250- 
253.

7. Baydur A, Behrakis PK, Zin WA, J aeger M \& Milic-Emili J (1982). A simple method of assessing the validity of the esophageal baloon technique. American Review of Respiratory Disease, 126: 788-791.

8. Kochi T, Okubo S, Zin WA \& Milic-Emili J (1988). Chest wall and respiratory system mechanics in cats: effects of flow and volume. J ournal of Applied Physiology, 64: 2636-2646.

9. Similowski T, Levy P, Corbeil C, Albala M, Pariente R, Derenne J P, Bates J HT, J onson B \& Milic-Emili J (1989). Viscoelastic behavior of lung and chest wall in dogs determined by flow internuption. J ournal of Applied Physiology, 67: 2219-2229.

10. Bates J HT, Rossi A \& Milic-Emili J (1985). Analysis of the behavior of the respiratory system with constant inspiratory flow. J ournal of Applied Physiology, 58: 18401848.

11. Bates J HT, Baconnier P \& Milic-Emili J (1988). A theoretical analysis of the interrupter technique for measuring respiratory mechanics. J ournal of Applied Physi- ology, 64: 2204-2214.

12. Bates JHT, Ludwig MS, Sly PD, Brown KA, Martin J O \& Fredberg JJ (1988). Intemupter resistance elucidated by alveolar pressure measurements in open-chest normal dogs. J oumal of Applied Physiology, 65: 408-414.

13. D'Angelo $E$, Calderini B, Torri G, Robbato FM, Bono D \& Milic-Emili J (1989). Respiratory mechanics in anesthetized paralyzed humans: effects of flow, volume, and time. J ournal of Applied Physiology, 67: 2556-2564.

14. Agostoni E, Thimm FF \& Fenn WO (1959). Comparative features of the mechanics of breathing. J ournal of Applied Physiology, 14: 679-683.

15. Weibel ER (1990). Morphometry: stereological theory and practical methods. In: Gil J (Editor), Models of Lung Disease Microscopy and Structural Models. Marcel Dekker, New York, 199-247.

16. Hemming A, MacKenzie I \& Finfer S (1994). Response to ketamine in status asthmaticus resistant to maximal medical treatment. Thorax, 49: 90-91.
17. Leff A (1989). Endogenous regulation of bronchomotor tone. American Review of Respiratory Disease, 137: 1198-1216.

18. Lehane J R (1982). Assessment of pulmonary airway calibre. British J oumal of Anaesthesia, 54: 751-761.

19. Reta GS, Riva J A, Piriz $\mathrm{H}$, Medeiros AS, Rocco PRM \& Zin WA (2000). Effects of halothane on respiratory mechanics and lung histopathology in normal rats. British J oumal of Anaesthesia, 84: 372-377.

20. Gateau O, Bourgain J L, Gaudy JH \& Benveniste J (1989). Effects of ketamine on isolated human bronchial preparations. British J ournal of Anaesthesia, 63: 692695.

21. Schulman D, Beardsmore CS, Aronson HB \& Godfrey S (1985). The effect of ketamine on the functional residual $\mathrm{Ca}$ pacity in young children. Anesthesiology, 62: 551-556.

22. Mankikian B, Cantineau JP, Sartene R, Clergue F \& Viars P (1986). Ventilatory pattem and chest wall mechanics during ketamine anesthesia in humans. Anesthesiology, 65: 492-499. 